\title{
A multilayer panel in cork and natural phase change materials: thermal and energy analysis
}

\author{
Domenico Mazzeo ${ }^{1, *}$, Nicoletta Matera ${ }^{1}$, Natale Arcuri ${ }^{1}$, and Francesco Barreca ${ }^{2}$ \\ ${ }^{1}$ Department of Mechanical, Energy and Management Engineering (DIMEG), University of Calabria, \\ P. Bucci 46C, 87036 Rende (CS), Italy \\ ${ }^{2}$ Department of Agriculture, Mediterranean University of Reggio Calabria, Località Feo di Vito, \\ 89122 Reggio Calabria, Italy
}

\begin{abstract}
This paper presents thermal and energy analysis of a multilayer panel in bio-based cork material and natural phase change materials (PCMs) for the development of prefabricated, recyclable and energyefficient and autonomous building modules. For this purpose, a calculation tool is developed for the dynamic simulation of the thermal and energy behaviour of the sandwich panel. In particular, through an extensive parametric survey, the panel is sized with the identification of the arrangement of the layers, PCM temperature, and layer thicknesses to optimize the insulating and damping properties, considering typical climatic conditions of the Mediterranean climates of Southern Italy. From the conducted simulations, the types of sandwich panels that have the best insulating and storage characteristics for the building module construction were chosen. The results of these simulations will be used in future research for the preliminary design of tests to be carried out in a climatic chamber and to build a building module in real conditions to be constantly monitored through the automatic instrumental survey of internal and external physical quantities such as temperature, humidity and radiant temperature.
\end{abstract}

\section{Introduction}

In the last decade, research has focused attention on the significant benefits generated by the use of biomaterials in construction and has unequivocally demonstrated that their physical and mechanical characteristics are not inferior to those of commonly used materials and coming from production processes that use non-renewable elements. In addition, they have additional advantages such as the reduction of the environmental impact, the ease of recycling and reuse and the possibility of obtaining raw material from agricultural and food industry production waste with a consequent reduction in the amount of waste to be disposed of. Furthermore, their use also has economic advantages generated both by their easy availability on the national territory and by the reduced production costs of the finished product.

\footnotetext{
${ }^{*}$ Corresponding author: domenico.mazzeo@\#unical.it
} 
The "Suberwall" research project developed in recent years by the Mediterranean University of Reggio Calabria had, as its final objective, the enhancing of the performance characteristics of the biocompatible, ecological and biodegradable material cork for the development of an energy-autonomous living cell with high flexibility both in terms of space and use [1]. The pressing demand for housing settlements arising also from emergencies (reception centres, environmental disasters, mobile construction sites, etc.) has pushed the market towards the production of housing that is both easy and ready to build with high standards of comfort and sustainability. The aim is to realize building modules with prefabricated components, designed to be easily assembled while possessing high flexibility and the ability to realize functional schemes variable also in time, according to the operational needs arising from different areas of use such as residential, hospitality, emergency, educational, productive, temporary or permanent. The research activity previously carried out by the Suberwall project has highlighted not only the thermal insulating properties of cork but has also highlighted that these characteristics can be improved by combining other natural materials, given the reduced heat capacity of cork [2].

The current project entitled "Modular building modules in wood and cork with high energy and environmental performance (SUSTANZEB)", provides for the construction of a multilayer cork panel starting from the "Suberwall" project, in collaboration between the Mediterranean University of Reggio Calabria and the University of Calabria. In this project, evident and substantial innovations are envisaged such as the addition of phase change materials (PCMs) of natural origins such as beeswax, vegetable oils, animal fats, non-toxic hydrated salts. PCMs have found noticeable applications in agricultural engineering to thermally control rooms containing specific products [3]. The proposed project SUSTANZEB aims to improve the panel thermal capacity, a particularly useful feature for the improvement of the thermal performance of the walls in hot climates characterized by high daily temperature ranges. By exploiting the heat stored by PCMs in the solid-liquid phase transformation, it is possible to limit temperature fluctuations within an environment and reduce heating and cooling energy requirements. Consequently, it will be possible to create a self-assembling housing module in cork agglomerate with the inclusion of natural origin PCMs characterized by both high resistance thermal and storage capacity even with reduced thicknesses, thus determining a high damping action of the thermal excursion both in winter and summer. Within the eco-sustainable construction sector, it is essential to adopt innovative technological systems and materials to compensate for the lack of synchronism between demand and production of thermal energy and to favour the increase of thermal inertia, the reduction of costs, and the reduction of polluting emissions.

Among these, latent thermal energy storage, created in the walls of buildings using PCMs, represents a futuristic and potentially decisive application. Starting from these concepts, this paper aims to study the thermal and energy behaviour of the cork-PCM sandwich panel in a typical Mediterranean area, Reggio Calabria, Italy.

\section{Materials and method}

To predict the energy performance of the Suberwall understudy, numerical investigations were carried out using the EnergyPlus dynamic simulation software [4].

The analyses can be divided into the following phases:

- the first phase consists of the definition of an adiabatic cavity in which the wall under study is the only one that actively contributes to the heat balance of the air node of the cavity;

- the second phase involves establishing with which Suberwall configuration, considering the different thicknesses of the cork layer, the seasonal and annual 
thermal performance of the panel are improved when a PCM layer is integrated; in this regard, different PCM positioning and melting temperatures were considered.

This investigation aims to identify the most suitable Suberwall to interact with a PCM layer, allowing the phase transition to be activated more frequently and the consequent benefit deriving from the latent storage process.

\subsection{Suberwall module stratigraphy}

The four Suberwall wall configurations considered are characterized by the use of two layers of cork on the outer side of the wall and two air spaces separated by an OSB layer.

Table 1. Surface thermophysical and optical properties of the Suberwall layers [1].

\begin{tabular}{|c|c|c|c|c|c|c|c|}
\hline Layer & $\begin{array}{l}\text { Thermal } \\
\text { conductivity } \\
(\mathrm{W} / \mathrm{mK})\end{array}$ & $\begin{array}{l}\text { Specific } \\
\text { heat } \\
\text { capacity } \\
(\mathrm{J} / \mathrm{kgK})\end{array}$ & $\begin{array}{l}\text { Density } \\
\left(\mathrm{kg} / \mathrm{m}^{3}\right)\end{array}$ & $\begin{array}{l}\text { Thermal } \\
\text { resistance } \\
\left(\mathrm{m}^{2} \mathrm{~K} / \mathrm{W}\right)\end{array}$ & $\begin{array}{c}\text { Emissivity } \\
(-)\end{array}$ & $\begin{array}{c}\text { Solar } \\
\text { absorbance } \\
(-)\end{array}$ & $\begin{array}{c}\text { Visible } \\
\text { absorbance } \\
(-)\end{array}$ \\
\hline $\begin{array}{c}\text { Cork } \\
\text { (external } \\
\text { side) } \\
\end{array}$ & 0.052 & 2491.9 & 145.85 & & 0.94 & 0.30 & 0.30 \\
\hline Air gap & & & & 0.18 & 0.90 & 0.70 & 0.70 \\
\hline $\begin{array}{c}\text { Oriented } \\
\text { Strand } \\
\text { Board } \\
(\text { OSB }) \\
\end{array}$ & 0.15 & 2700 & 550 & & 0.60 & 0.60 & 0.60 \\
\hline Air gap & & & & 0.18 & 0.90 & 0.70 & 0.70 \\
\hline $\begin{array}{c}\text { Cork } \\
\text { (internal } \\
\text { side) }\end{array}$ & 0.052 & 2491.9 & 145.85 & & 0.94 & 0.30 & 0.30 \\
\hline
\end{tabular}

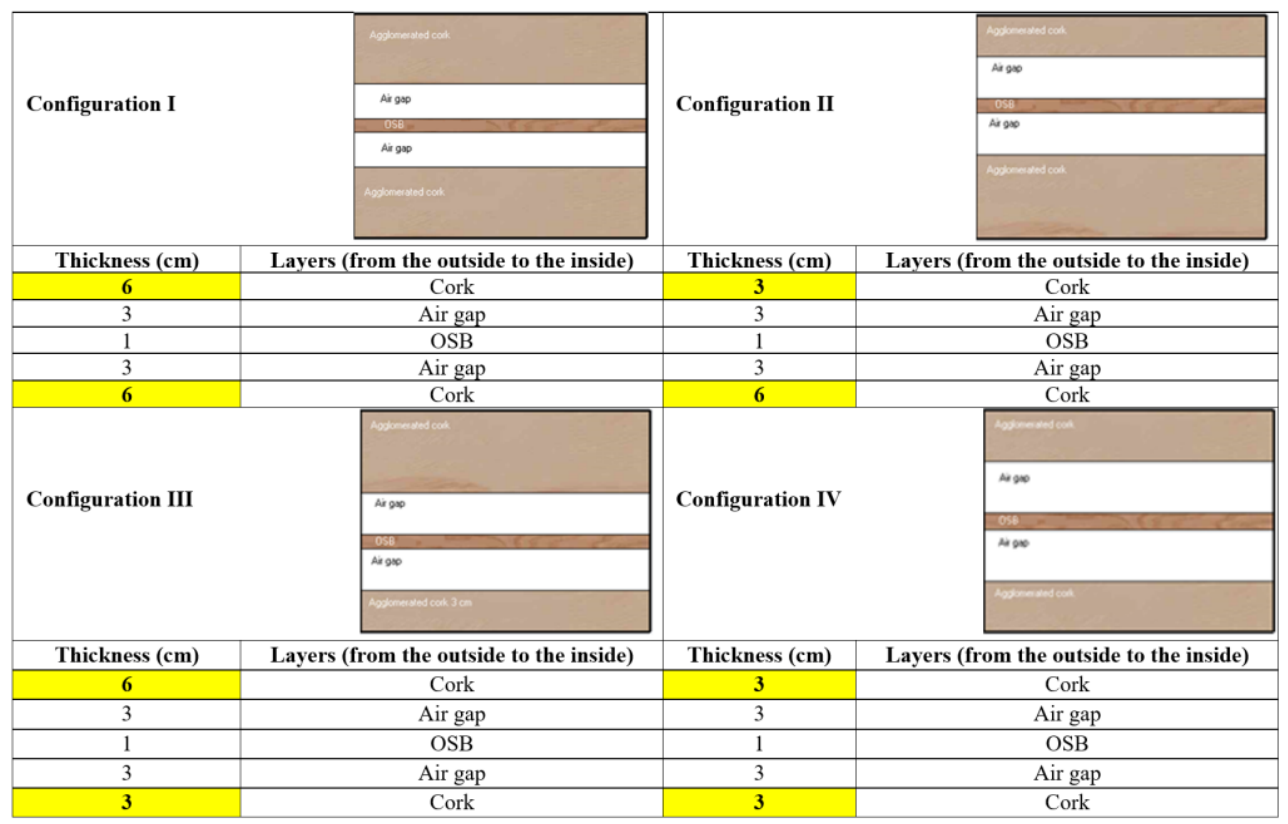

Fig. 1. Configuration I, II, III, IV of the Suberwall. 
The only difference between the configurations is due to the different thicknesses of cork used on the external and/or internal surfaces. Table 1 reports the surface thermophysical and optical properties of the different layers, while Table 2 illustrates the different stratigraphies considered.

\subsection{Climatic conditions}

The hourly climatic file epw of Messina (Italy) from the DesignBuilder library was used in all analyses because it is a locality with climatic characteristics very similar to those of Reggio Calabria, the locality under study. Reggio Calabria belongs to climate zone B according to the Ministerial Decree of June 16, 2015 [5]. Figure 2 shows the trend of the monthly mean daily temperature, monthly diffuse, direct and total solar radiation.

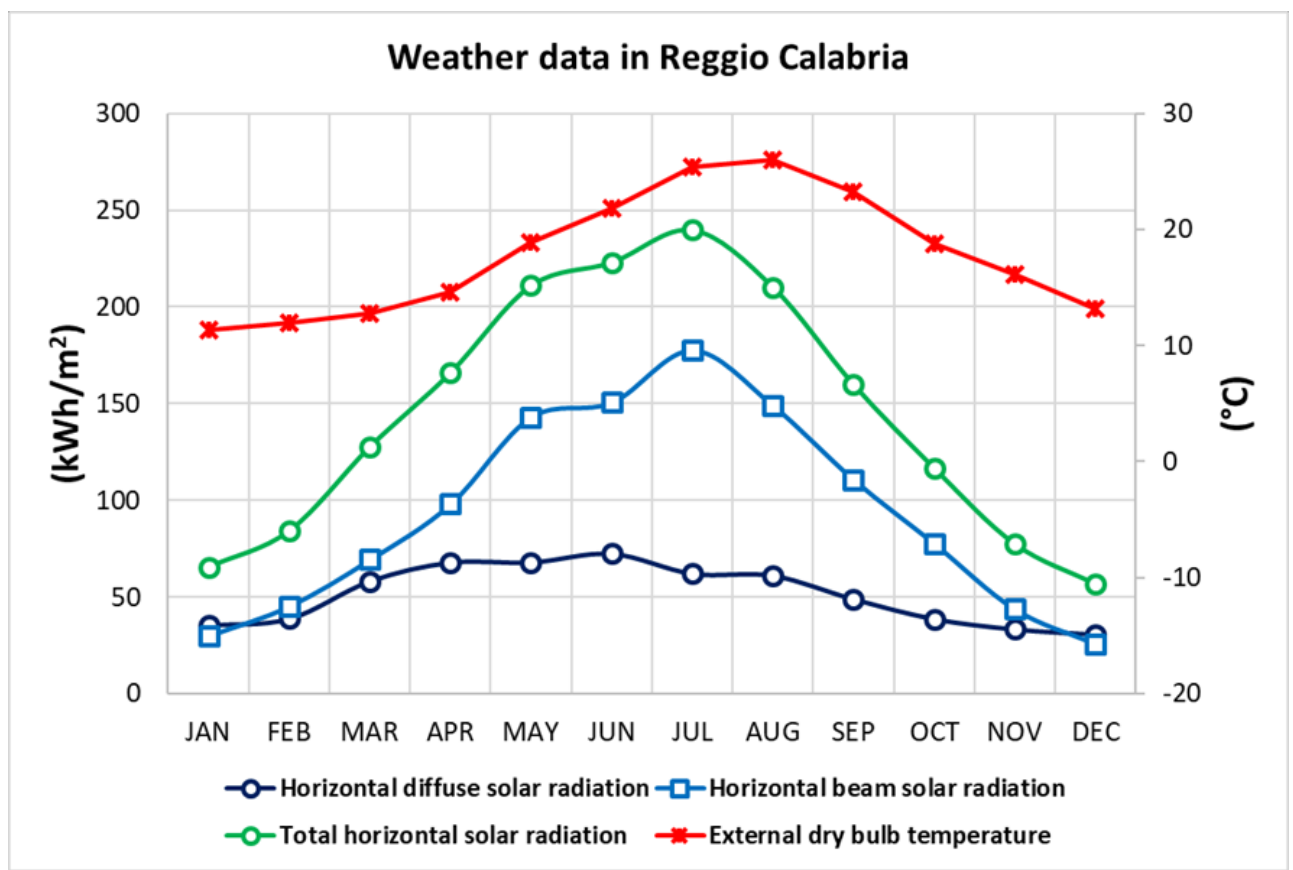

Fig. 2. Monthly average daily external air temperature, diffuse, direct and total monthly solar radiation in Reggio Calabria.

\subsection{PCM simulation}

PCMs are materials that store energy in the form of latent heat capable of storing large amounts of energy even with small temperature changes. The phase change occurs at a practically constant temperature and therefore, they are widely used as stabilizing and temperature control agents of the system in which they are integrated. It should be emphasized that each latent heat storage system also has a storage rate of sensible heat, resulting in much higher overall storage capacities than those of conventional materials. The advantages related to the use of these materials are, however, strongly dependent on the choice of material for the specific application. The currently most widely used software for dynamic simulation of the thermal behaviour of building components integrated with PCMs are the TRaNsient SYstem Simulation (TRNSYS), IDA ICE and EnergyPlus [4, 68]. Regarding the mathematical treatment of heat transfer in a PCM layer, TRNSYS employs the simplified concentrated parameter method requiring a reduced number of input 
quantities leading to lower accuracy. On the other hand, IDA ICE and EnergyPlus employ the enthalpy method and require the thermal conductivity, specific heat and density in the two phases and the enthalpy-temperature variation curves in the melting and solidification process as input data. The latter option allows consideration of the hysteresis phenomenon. After a careful analysis of the mathematical models used by BPS (Dynamic Building Performance Simulation) software considered to predict the thermal behaviour of a building whose walls are integrated with PCM, EnergyPlus was chosen to perform the numerical investigation object of this activity, namely the study of the dynamic thermal behaviour of the Suberwall with PCM.

EnergyPlus is a powerful dynamic energy simulation engine, developed by the U.S. Department of Energy, based on a continuously updated modular framework, which is easy to use through the graphical interface provided by DesignBuilder [9]. DesignBuilder is advanced software that consists of an integrated interface of tools for designing and evaluating the thermo-energetic behaviour of buildings. It contains a 3D modeller for the generation of the three-dimensional model to be simulated. EnergyPlus offers a choice of two methods for modelling PCMs [10-12]:

- Basic method (temperature-enthalpy method) that uses the same temperatureenthalpy curve for both the melting and solidification processes. Temperature and enthalpy values are required as input in a two-column tabular function. The software gives the option of selecting from 1 to 16 points. The number of points selected will determine the number of points available for temperature and enthalpy data input. The specific heat Eq. (1) is calculated from the input data of the entered enthalpytemperature point pairs:

$$
\mathrm{C}_{\mathrm{p}}=\frac{\mathrm{h}_{\mathrm{i} \text {,new }}-\mathrm{h}_{\mathrm{i} \text {,prev }}}{\mathrm{T}_{\mathrm{i} \text { new }}-\mathrm{T}_{\mathrm{i} \text {,prev }}}
$$

where $C_{p}$ is the specific heat and $T_{i}$ and $h_{i}$ are the temperature and enthalpy at the $i-$ th node in the previous prev and next new instants. The main limitation of the basic method is that the use of a single temperature-enthalpy curve can lead to high accuracy errors when simulating a PCM with pronounced hysteresis. This limitation with the new versions of EnergyPlus (released on September 27, 2019) has been solved, implementing a new model that considers the hysteresis phenomenon.

- Hysteresis method that allows modelling the two temperature-enthalpy curves during the melting and solidification process. In particular, this option requires the characteristics of the enthalpy-temperature curves, such as the temperature at which the maximum accumulation or release of latent energy occurs and temperature differences that allow reconstructing the shape of the curve around the maximum value. This allows for accurate modelling even when the user does not have the detailed data needed to generate the temperature-enthalpy curve. In this case, the specific heat Eq. (2) is not only dependent on the current state but also on the previous state, since it considers the hysteresis phenomenon present between the melting and solidification processes:

$$
\mathrm{C}_{\mathrm{P}}=\mathrm{f}\left(\mathrm{T}_{\mathrm{i}, \text { new }}, \mathrm{T}_{\mathrm{i}, \text { prev }}, \text { PhaseState }_{\text {new }} ; \text { PhaseState }_{\text {prev }}\right)
$$

The thermal conductivity, specific heat, and density values of the PCM are required for both the liquid and solid phases, while the average is used in the transition region. In addition, the hysteresis approach requires the latent heat during the entire phase change process $(\mathrm{J} / \mathrm{kg})$, which is the total amount of latent heat accumulated or 
released by the material during the melting and solidification process. Of the two methods described to simulate the energy performance of the Suberwall, the one that accounts for hysteresis being the most accurate was chosen. The method with hysteresis models the same process but also includes a hysteresis effect, allowing the melting and solidification processes to follow different curves, representing an effect commonly found in building envelope PCM applications. This option also allows you to enter characteristic properties of the processes instead of a detailed temperature/enthalpy curve, making it more suitable for studies where the user does not have the detailed test data needed to generate the temperature/enthalpy curve. In particular, in addition to requiring the latent heat accumulated or released of the entire process and the thermophysical properties of the PCM, thermal conductivity, specific heat and density, in the two phases, requires individually for the two processes of melting and solidification:

○ High-temperature difference, which is the width of the enthalpy/specific heat curve on the upper side of the peak temperature;

- Low-temperature difference, which is the width of the enthalpy/specific heat curve on the lower side of the peak temperature;

- Peak temperatures, which are the temperatures with which the maximum accumulation or release of latent energy is associated,

Normally, the peak temperature of solidification is greater than that of melting. Although the melting and solidification enthalpy curves have different shapes, the total amount of latent energy from one state to the other is the same.

Two natural InfiniteR PCMs produced by Insolcorp [13] and distributed in Italy by e4e Phase Change Material High-Tech [14] are considered; they differ only in the temperature at which the peak latent energy storage occurs, namely $21^{\circ} \mathrm{C}$ and $25^{\circ} \mathrm{C}$, see Table 2 .

Table 2. Thermophysical properties of InfiniteR natural PCM.

\begin{tabular}{|c|c|c|}
\hline PCM & \multicolumn{2}{|c|}{$21^{\circ} \mathrm{C} / 25^{\circ} \mathrm{C}$ Infinite $\mathrm{R}$} \\
\hline Heat latent of fusion $(\mathrm{J} / \mathrm{g})$ & \multicolumn{2}{|c|}{200} \\
\hline & Solid phase & Liquid phase \\
\hline Thermal conductivity $(\mathrm{W} / \mathrm{mK})$ & 1.09 & 0.54 \\
\hline Specific heat capacity $(\mathrm{kJ} / \mathrm{kgK})$ & 3.14 & 3.14 \\
\hline Density $\left(\mathrm{kg} / \mathrm{m}^{3}\right)$ & 1540 & 1540 \\
\hline
\end{tabular}

A thickness of $2 \mathrm{~cm}$ was considered for the 3 different placements, on the outer and inner surface of the wall and in the air gap; in the latter case, the thickness is distributed symmetrically with respect to the OSB layer in the two air gaps with $1 \mathrm{~cm}$ each.

\subsection{Definition of an adiabatic cavity}

To isolate the contribution of the wall understudy, a $4 \mathrm{~m} \mathrm{x} 4 \mathrm{~m} \mathrm{x} 4 \mathrm{~m}$ cavity was considered using the interface provided by DesignBuilder, whose walls are all adiabatic except for the Suberwall, assumed to be south-facing. In particular, a preliminary analysis has been carried out to establish under which conditions the energy contribution of the other five walls on the whole cavity can be considered negligible. The investigation has been carried out considering different alternatives

- $\quad$ considering the five walls consisting of a single insulating layer with a thickness of $50 \mathrm{~cm}$, or $100 \mathrm{~cm}$ or $150 \mathrm{~cm}$;

- $\quad$ selecting the "adiabatic" boundary condition option present in Designbuilder and considering a wall whose insulation thickness is $100 \mathrm{~cm}$ or $0.1 \mathrm{~cm}$. 
The thermophysical and optical characteristics of the considered insulation layer are shown in Table 3.

Table 3. Thermophysical and optical properties of the insulation layer.

\begin{tabular}{|c|c|c|c|c|c|c|c|}
\hline Layer & $\begin{array}{c}\text { Thermal } \\
\text { conductivity } \\
(\mathrm{W} / \mathrm{mK})\end{array}$ & $\begin{array}{c}\text { Specific } \\
\text { heat } \\
(\mathrm{J} / \mathrm{kgK})\end{array}$ & $\begin{array}{c}\text { Density } \\
\left(\mathrm{kg} / \mathrm{m}^{3}\right)\end{array}$ & $\begin{array}{c}\text { Thermal } \\
\text { resistance } \\
\left(\mathrm{m}^{2} \mathrm{~K} / \mathrm{W}\right)\end{array}$ & $\begin{array}{c}\text { Emissivity } \\
(-)\end{array}$ & $\begin{array}{c}\text { Solar } \\
\text { absorbance } \\
(-)\end{array}$ & $\begin{array}{c}\text { Visible } \\
\text { Absorbance } \\
(-)\end{array}$ \\
\hline Insulation & 0.001 & 100 & 20 & 0.99 & 0.01 & 0.01 & 0.001 \\
\hline
\end{tabular}

To verify the incidence of the various walls constituting the cavity on the thermal balance of the air node, the results of the dynamic simulations have been summarized through the use of the energies associated with the thermal flows transferred from each wall to the air node, with the convention that the flow goes from the outside to the inside, i.e. incoming and typical of the summer season, and one related to the energies associated with the flows directed from the inside to the outside, i.e. outgoing and typical of winter conditions.

$$
\mathrm{E}_{\mathrm{i}}^{+}=\sum_{\mathrm{k}}^{8760} \varphi_{\mathrm{k}, \mathrm{i}}^{+} \quad \mathrm{E}_{\mathrm{i}}^{-}=\sum_{\mathrm{k}}^{8760} \varphi_{\mathrm{k}, \mathrm{i}}^{-}
$$

With $\mathrm{E}_{\mathrm{i}}^{+}$and $\mathrm{E}_{\mathrm{i}}^{-}$, respectively, annual energy entering the indoor environment and leaving the indoor environment from the i-th wall, $\varphi_{\mathrm{k}}^{+}$and $\varphi_{\mathrm{k}}^{-}$heat flux entering the indoor environment and leaving the indoor environment from the i-th wall at the k-th hour of the year.

The results of these analyses can be represented by means of two pie charts, one relating to the $\mathrm{E}_{\mathrm{i}}^{+}$energies associated with the heat fluxes transferring from each wall to the air node, with the convention that the flux goes from the outside to the inside, i.e., incoming and typical of the summer season, and one relating to the $\mathrm{E}_{\mathrm{i}}^{-}$energies associated with the direct fluxes from the inside to the outside, i.e., outgoing and typical of winter conditions. In such pie charts, a fraction represents the contribution of a specific wall. The results in Figure 3 concern configuration I like the thickness of insulation used in the 5 "adiabatic" walls of the cavity varies.

The south-facing Suberwall is the wall with the highest percentage of energy transferred to the indoor environment and the one that has the greatest influence on the air node balance. An increase in the thickness of the insulation, although it allows the percentage of total energy dispersed from the air node to the external environment through the Suberwall to be increased, gives rise to a reduction of the percentage of total energy transferred from the external environment to the air node through the same Suberwall. This is due to the increasing effect of the capacity of the other five insulating walls proportional to their thickness. Similarly, figure 4 shows the results obtained using the "adiabatic" option as the thickness of the insulation layer varies. 


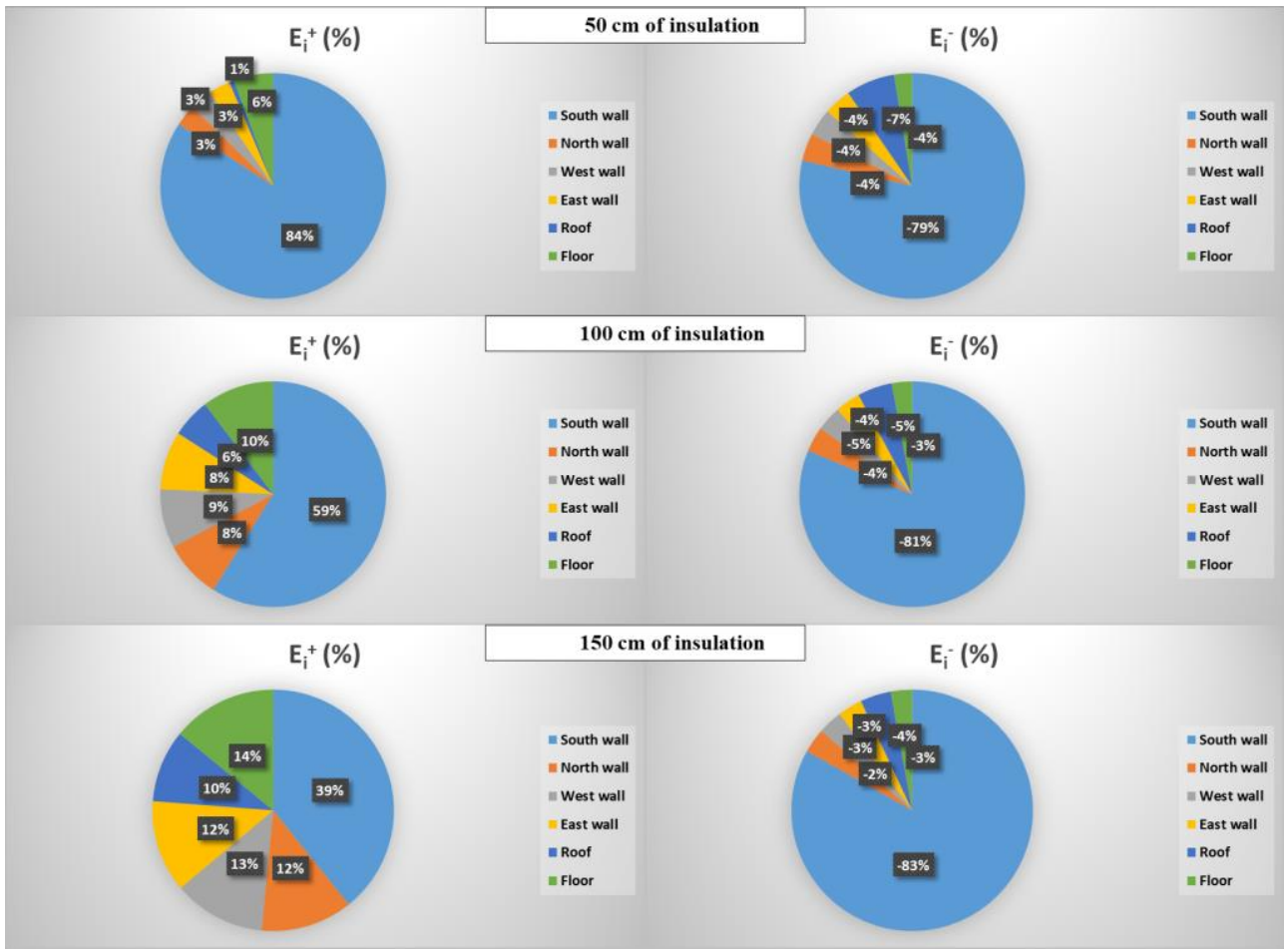

Fig. 3. Cavity with the Suberwall configuration I facing South and 50, 100 and $150 \mathrm{~cm}$ of insulation on the other walls.

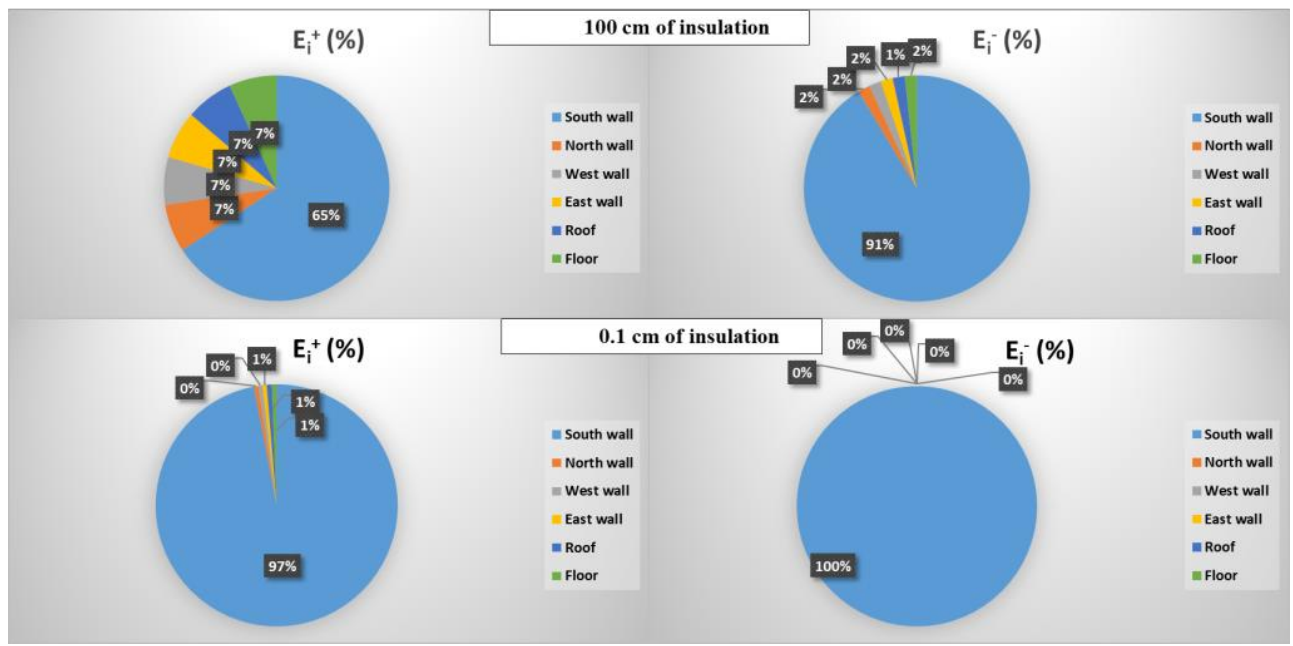

Fig. 4. Cavity with the Suberwall configuration I facing south and "adiabatic" boundary condition and $100 \mathrm{~cm}$ and $0.1 \mathrm{~cm}$ of insulation on the other walls.

The combined use of the "adiabatic" boundary condition and a reduced insulation thickness of $0.1 \mathrm{~cm}$ practically cancels out the energy transferred from the inside environment to the outside and vice versa through the five walls. Under these conditions, only the Suberwall transfers heat into and out of the cavity, making it the only wall that affects the air node balance and the resulting fluctuation in indoor air temperature. This verification remains confirmed for the other Suberwall configurations as well. For this reason, these conditions 
will be used in the following analysis to evaluate the performance of the Suberwall provided with a PCM layer.

\subsection{Impact of PCM layer integration in different Suberwall configurations}

The study involves evaluating the conditions under which the solid-liquid phase transition is most frequently activated and, consequently, the thermal performance of the walls is drastically improved. In particular, through the use of the adiabatic cavity, the objective of this analysis is to identify which configuration of Suberwall (thickness of the cork layers), positioning (on the inner surface, on the outer surface or in the air gap of the Suberwall) and temperature of the PCM lead to air temperatures inside the cavity closer to the conditions of well-being typical of the occupants. Two indicators for the winter and summer seasons are used to evaluate the intensity of thermal discomfort in the cavity.

The winter thermal discomfort intensity $\mathrm{TDI}_{\mathrm{w}}$ and summer thermal discomfort intensity $\mathrm{TDI}_{\mathrm{s}}$ measure the distance in ${ }^{\circ} \mathrm{C}$ from the ideal winter and summer comfort temperatures, respectively.

$$
\begin{array}{lll}
\mathrm{TDI}_{\mathrm{w}}=\sum_{\mathrm{h}}\left(20^{\circ} \mathrm{C}-\mathrm{T}_{\mathrm{ai}, \mathrm{h}}\right) & \text { if } & \mathrm{T}_{\mathrm{ai}, \mathrm{h}}<20^{\circ} \mathrm{C} \\
\mathrm{TDI}_{\mathrm{s}}=\sum_{\mathrm{h}}\left(\mathrm{T}_{\mathrm{ai}, \mathrm{h}}-26{ }^{\circ} \mathrm{C}\right) & \text { if } & \mathrm{T}_{\mathrm{ai}, \mathrm{h}}>26^{\circ} \mathrm{C}
\end{array}
$$

Instead, to evaluate the energy performance of the wall the energies $\mathrm{E}_{\mathrm{i}}^{+}$and $\mathrm{E}_{\mathrm{i}}^{-}$transferred by the Suberwall will be evaluated.

These indices are evaluated for all cases considered. The higher the index, the larger the temperature deviation in the interior rooms from the ideal comfort temperatures.

To identify the impact of the presence of the PCM layer, the percentage change of these quantities in comparison to the case without PCM will be evaluated for the different placements and phase change temperatures of the PCM considered.

As described, some parameters substantially modify the thermal behaviour of a wall provided with PCM.

\section{Results}

Figures 5-8 show the results obtained considering the 4 Suberwall configurations, varying the PCM position and phase change temperature.

In general, TDI in the winter season is slightly lower using configuration I and increases by switching to configuration IV. In contrast, summer TDI is lowest with configurations II and III and highest with configuration IV.

In the winter season, employing the PCM on any Suberwall configuration results in reduced TDI for all PCM positions and phase change temperatures. For all Suberwall configurations, a temperature of $21^{\circ} \mathrm{C}$ leads to a greater reduction in winter TDI, while the TDI cancels out by integrating the PCM on the interior surface regardless of the phase change temperature. Consequently, placing a PCM with a phase change temperature of 21 ${ }^{\circ} \mathrm{C}$ on the inner surface of any Suberwall results in the best winter performance. 


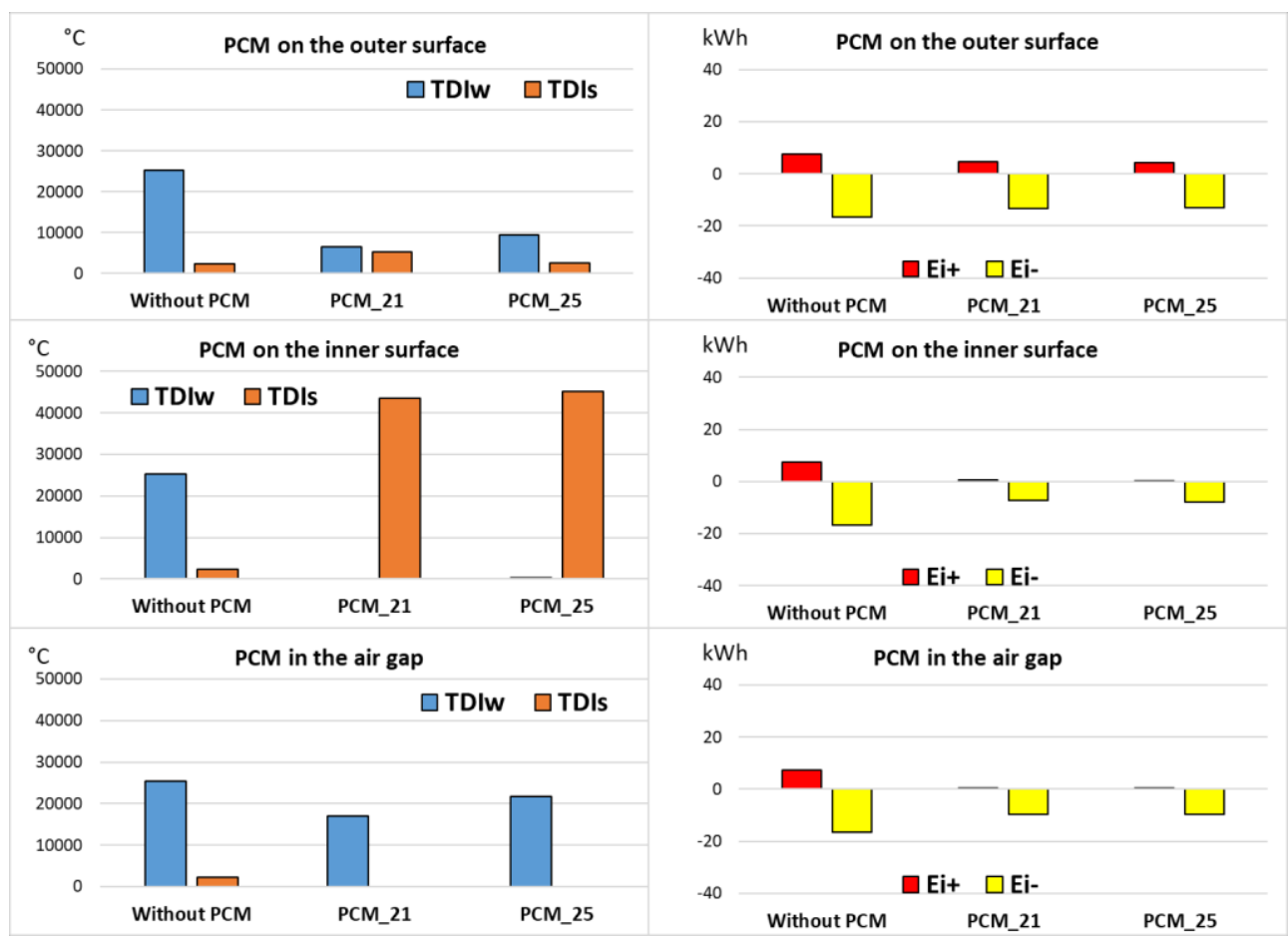

Fig. 5. Thermal and energy results of the Suberwall configuration I with PCM.

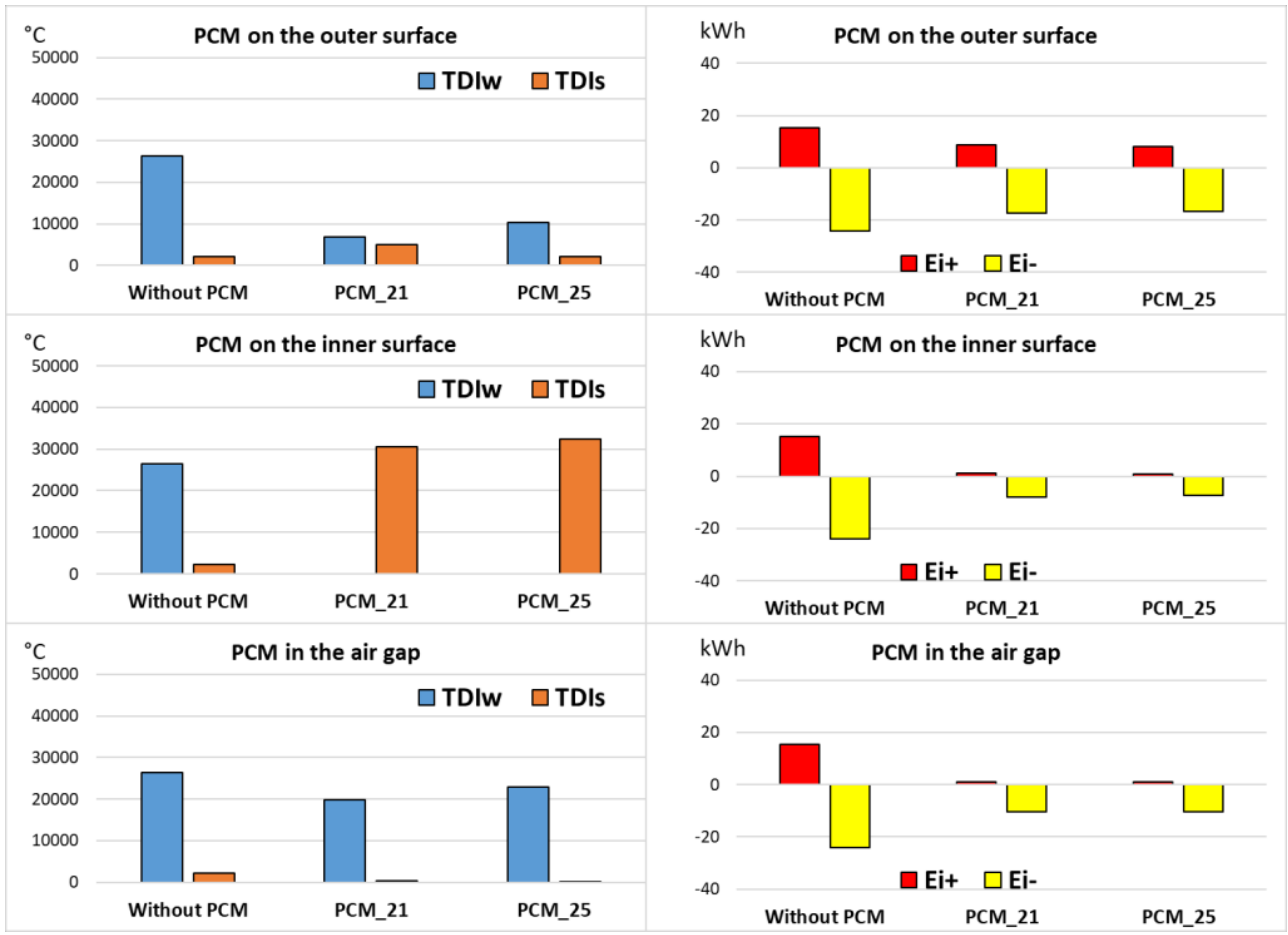

Fig. 6. Thermal and energy results of the Suberwall configuration II with PCM. 


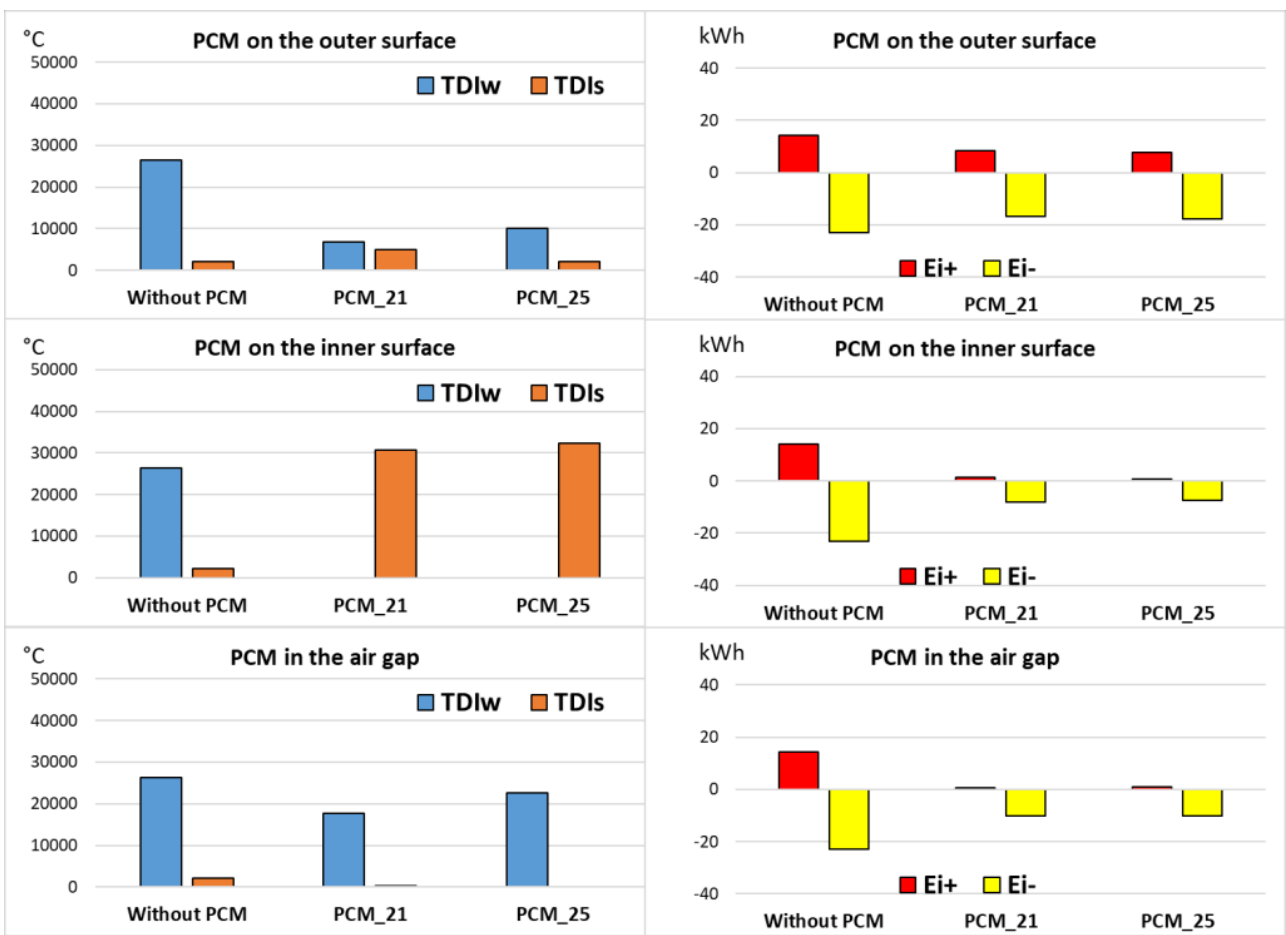

Fig. 7. Thermal and energy results of the Suberwall configuration III with PCM.

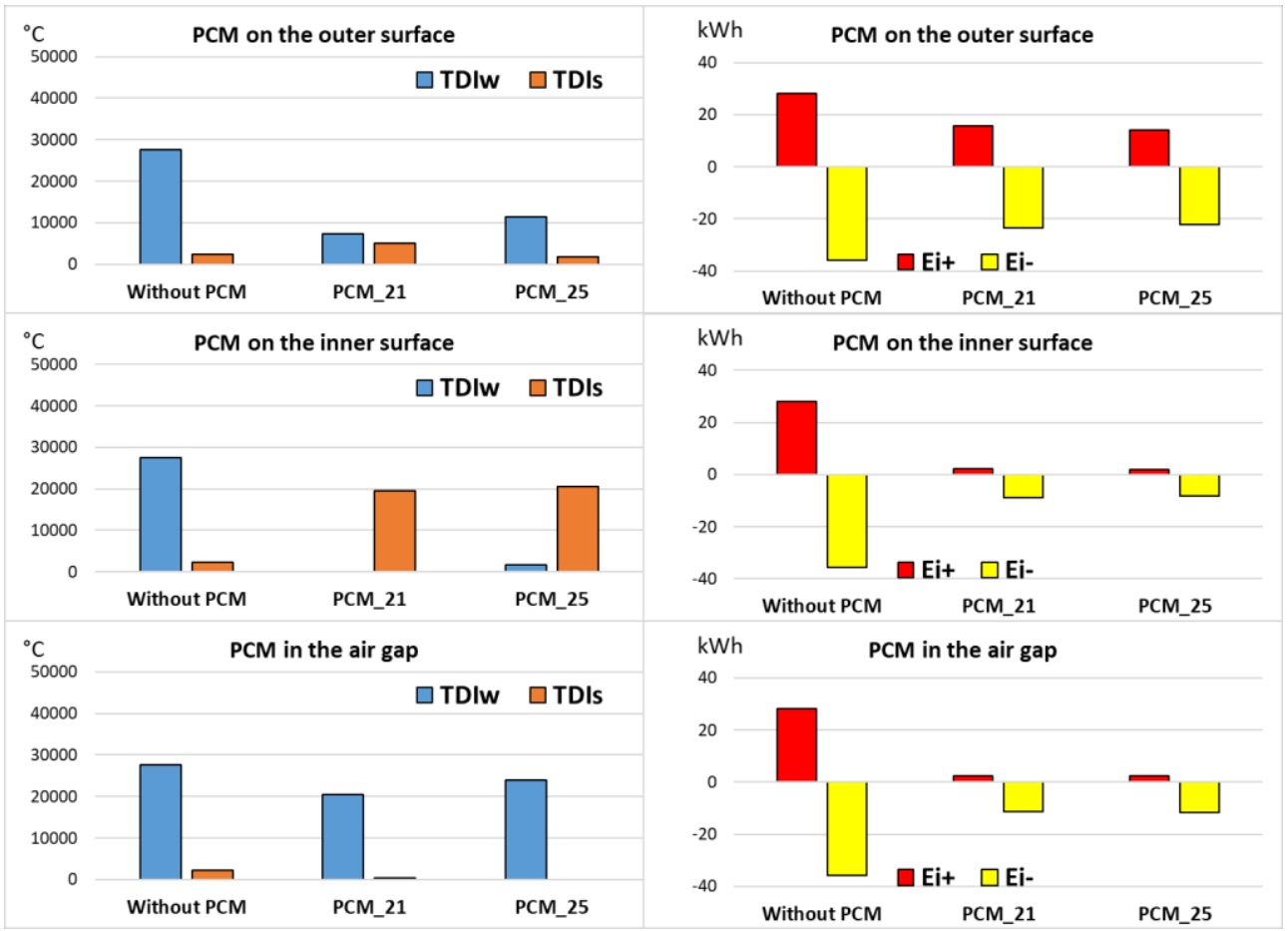

Fig. 8. Thermal and energy results of the Suberwall configuration IV with PCM. 
In the summer season, using the PCM on any Suberwall wall configuration leads to a reduction in TDI by placing the PCM in the air gap for any phase change temperature, while it leads to a slight increase by placing the PCM on the exterior surface and a dramatic increase by placing the PCM on the interior surface for any phase change temperature. For all Suberwall configurations, a temperature of $25^{\circ} \mathrm{C}$ leads to a larger reduction and smaller increase in summer TDI for the various Suberwall configurations, while the TDI is almost nil by integrating the PCM into the air gap regardless of the phase change temperature. Consequently, placing a PCM with a phase change temperature of $25{ }^{\circ} \mathrm{C}$ in the air gap of any Suberwall will lead to the best summer performance.

The energies transferred from the wall to the external environment $E_{i}^{-}$and to the internal environment, $\mathrm{E}_{\mathrm{i}}^{+}$are minimal in the absence of PCM using configuration I, while configuration IV is the worst leading to higher values of energies.

The integration of the PCM leads in all cases to a reduction of $\mathrm{E}_{\mathrm{i}}^{-}$and $\mathrm{E}_{\mathrm{i}}^{+}$. The reductions in $\mathrm{E}_{\mathrm{i}}^{-}$and $\mathrm{E}_{\mathrm{i}}^{+}$result in little dependence on the phase change temperature. The energy transferred to the external or internal environment is minimal by interposing the PCM in the air gap or on the internal surface.

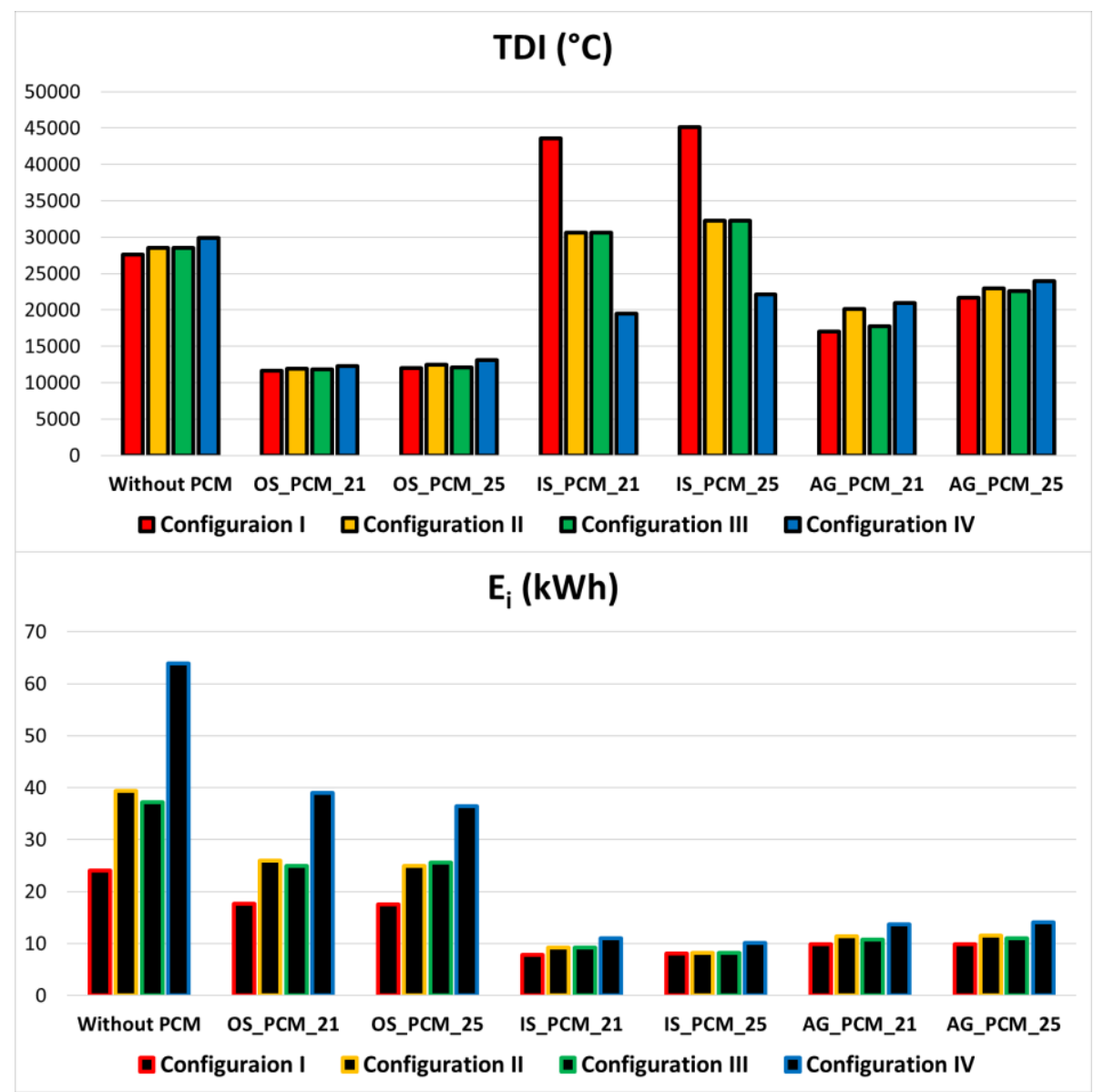

Fig. 9. Annual thermal discomfort intensity and energy transferred to the external and internal environment for the 4 Suberwall configurations as the placement and phase change temperature of the PCM vary. OS (outer surface), IS (inner surface), AG (air gap). 
To define the Suberwall most suitable to interact with the PCM, the annual values of thermal discomfort intensity and transferred energies, obtained as the sum in absolute value between the summer and winter value, have been calculated at the variation of the positioning and the phase change temperature of the PCM and reported in figure 9.

From a careful analysis of the two figures, the configuration I guarantees the lowest values of TDI and E, except in terms of TDI when integrated on the inner surface. Vice versa, for configuration IV of Suberwall. The highest comfort intensity is obtained by integrating the PCM on the outer surface of Suberwall configuration I for both phase change temperatures. In contrast, in terms of energy $E_{i}$, the Suberwall Configuration I allows the transfer to be limited by placing the PCM on the inner surface for both phase change temperatures. Ultimately, the configuration I is the most suitable wall to host a PCM layer.

\section{Conclusions}

The objective of this paper is the study of the thermal and energy performance of an innovative wall composed of only biomaterials, such as cork and PCMs, in the framework of a current project involving the Mediterranean University of Reggio Calabria and the University of Calabria. The coupling of PCM layers with agglomerated cork panels is certainly appropriate from the thermal point of view. A cork layer has a high thermal conductive resistance and a reduced frontal thermal capacity; it is, therefore, unsuitable because of the reduced thermal inertia to dampen and phase out the peaks of the loads produced by the thermal forcing that operate mainly in summer on the outer surface of the building envelope. One way to give a cork wall suitable dynamic thermal capacity is to couple it with layers of PCM which increase the capacity of thermal storage.

In this study, a numerical model was developed on DesignBuilder to determine the thermal and energy behaviour of a sandwich panel that includes two layers of agglomerated cork, and layers of PCM "Infinite R" produced by Insolcorp. This PCM was chosen because of its natural origin and because it is available in a wide range of phase change temperatures that lie below and above the $20-26^{\circ} \mathrm{C}$ air temperature band that affects room air conditioning.

The numerical model developed dynamically simulates the thermal behaviour of a cubic-shaped test module with five adiabatic walls and one conducting test wall. For this purpose, an adiabatic cavity was considered in which the Suberwall combined with the PCM wall is the only thermally "active" and affecting the temperature of the air node of the cavity. The model makes it possible to determine the thermal and energy behaviour of the test wall subjected to external climatic conditions of a typical Mediterranean locality in a one-directional heat conduction condition. In particular, four different configurations of the Suberwall module without PCM were studied by means of an extensive parametric survey carried out using the EnergyPlus software, obtained by varying the thickness of the cork in the outer and inner surface layer of the wall. For each of the four configurations, the effect of the inclusion of the PCM material was investigated when varying the phase change temperature and the position of the PCM (on the internal surface, on the external surface or in the air gap of the Suberwall). The analysis was summarized on a seasonal (summer and winter) and yearly basis by means of the thermal discomfort index and the overall energies entering and exiting the wall from the inner surface.

The results allow designers to identify the most suitable cork-PCM combination leading to the most reduced energy exchanges through the modular building proposed and the best thermal comfort conditions.

The work was funded by the Italian Ministry of Education, University and Research. The research leading to these results has received funding from the PROGRAMMA NAZIONALE RICERCA 
2015/2020-Progetto "Proof of Concept" - DECRETO MIUR N. 497 DEL 02/03/2018, Fondo di sviluppo e coesione (FSC) under grant agreement "Moduli edilizi componibili in legno e sughero ad elevate prestazioni energetiche ed ambientali (SUSTANZEB)" - POC01_00052 - CUP H84I19000240008.

\section{References}

1. F. Barreca, V. Tirella, A self-built shelter in wood and agglomerated cork panels for temporary use in Mediterranean climate areas, Energy and Buildings, Volume 142, 2017, Pages 1-7, ISSN 0378-7788, https://doi.org/10.1016/j.enbuild.2017.03.003.

2. F. Barreca, G.D. Cardinali, C.R. Fichera, P. Praticò, Utilization of cork residues for high performance walls in green buildings, Agricultural Engineering International: CIGR Journal, Volume 20 (1), 2018, Pages 47-55, ISSN 1682-1130.

3. F. Barreca, P. Praticò, Environmental indoor thermal control of extra virgin olive oil storage room with phase change materials, Journal of Agricultural Engineering, Volume 50(4), 2019, n. 947, Pages 208-214, ISSN 2239-6268 https://doi.org/10.4081/jae.2019.947.

4. Building Technologies Office of U.S. Department of Energy's (DOE) Building Technologies Office (BTO) (2016). EnergyPlus ${ }^{\mathrm{TM}}$ 8.6. Available online: https://energyplus.net/ (accessed on 15 March 2020).

5. Decreto Ministeriale 26 giugno 2015. Applicazione delle metodologie di calcolo delle prestazioni energetiche e definizione delle prescrizioni e dei requisiti minimi degli edifici.

6. University of Wisconsin (2018). TRNSYS 18: A transient system simulation program. Solar Energy Laboratory. Available online: http://www.trnsys.com/ (accessed on 15 March 2020).

7. Equa Simulation AB (2018). IDA Indoor Climate and Energy 4.8. Available online: https://www.equa.se/en/ (accessed on 15 March 2020).

8. D. Mazzeo, N. Matera, C. Cornaro, G. Oliveti, P. Romagnoni, L. De Santoli, EnergyPlus, IDA ICE and TRNSYS predictive simulation accuracy for building thermal behaviour evaluation by using an experimental campaign in solar test boxes with and without a PCM module, Energy and Buildings, Volume 212, 2020, n. 109812, ISSN 0378-7788, https://doi.org/10.1016/j.enbuild.2020.109812.

9. DesignBuilder Software Ltd version 5.5.0 (2019). https://designbuilder.co.uk (accessed on 15 March 2020).

10. U.S. Department of Energy (2018). EnergyPlus ${ }^{\mathrm{TM}}$ Version 8.9 Documentation, Engineering Available online: https://energyplus.net/sites/all/modules/custom/nrel_custom/pdfs/pdfs_v8.9.0/Engineer ingReference.pdf (accessed on 15 March 2020).

11. A. Al-Janabi, M. Kavgic, Application and sensitivity analysis of the phase change material hysteresis method in EnergyPlus: A case study, Applied Thermal Engineering, Volume 162, 2019, n. 114222, ISSN 1359-4311, https://doi.org/10.1016/j.applthermaleng.2019.114222.

12. A. Zastawna-Rumin, T. Kisilewicz, U. Berardi, Novel Simulation Algorithm for Modeling the Hysteresis of Phase Change Materials, Energies Volume 13, 2020, n. 1200, https://doi.org/10.3390/en13051200.

13. Insolcorp, LLC, Albemarle, NC (United States) http://insolcorppcm.com/

14. e-4e Phase Change Material, Aosta (Italy), https://e-4epcm.it/ 